\title{
Unusual Target Selectivity of Perisomatic Inhibitory Cells in the Hilar Region of the Rat Hippocampus
}

\author{
László Acsády, ${ }^{1}$ István Katona, ${ }^{1}$ Francisco J. Martínez-Guijarro, ${ }^{1,2}$ Gyórgy Buzsáki, ${ }^{3}$ and Tamás F. Freund ${ }^{1}$ \\ 1/nstitute of Experimental Medicine, Hungarian Academy of Sciences, H-1450 Budapest, Hungary, ${ }^{2}$ Department of Cell \\ Biology, Faculty of Biology, University of Valencia, 46100 Burjasot, Spain, and ${ }^{3}$ Center for Molecular and Behavioral \\ Neuroscience, Rutgers, The State University of New Jersey, Newark, New Jersey 07102
}

\begin{abstract}
Perisomatic inhibitory innervation of all neuron types profoundly affects their firing characteristics and vulnerability. In this study we examined the postsynaptic targets of perisomatic inhibitory cells in the hilar region of the dentate gyrus where the proportion of potential target cells (excitatory mossy cells and inhibitory interneurons) is approximately equal. Both cholecystokinin (CCK)and parvalbumin-immunoreactive basket cells formed multiple contacts on the somata and proximal dendrites of mossy cells. Unexpectedly, however, perisomatic inhibitory terminals arriving from these cell types largely ignored hilar GABAergic cell populations. Eighty-ninety percent of various GABAergic neurons including other CCK-containing basket cells received no input from CCK-positive terminals. Parvalbumin-containing cells sometimes innervated each other but avoided $75 \%$ of other GABAergic cells. Overall, a single mossy cell received 40 times more CCK-immunoreactive terminals and 15 times more parvalbumin-positive terminals onto its soma
\end{abstract}

than the cell body of an average hilar GABAergic cell. In contrast to the pronounced target selectivity in the hilar region, CCK- and parvalbumin-positive neurons innervated each other via collaterals in stratum granulosum and moleculare.

Our observations indicate that the inhibitory control in the hilar region is qualitatively different from other cortical areas at both the network level and the level of single neurons. The paucity of perisomatic innervation of hilar interneurons should have profound consequences on their action potential generation and on their ensemble behavior. These findings may help explain the unique physiological patterns observed in the hilus and the selective vulnerability of the hilar cell population in various pathophysiological conditions.

Key words: hilus; dentate gyrus; mossy fiber; mossy cell; interneuron; hippocampus; perisomatic; inhibition; basket cell
The hilar region is in a critical position to control information flow from the entorhinal cortex to the hippocampus. Together with the dentate gyrus, it acts as a "gate" mechanism to limit the excitatory influences of the entorhinal input (Winson and Abzug 1978; Moser, 1996). The hilus is also one of the most vulnerable brain regions to various pathophysiological conditions, including epilepsy, brain trauma, and ischemia (Dam, 1980; Sloviter, 1987; Schmidt-Kastner and Freund, 1991; Lowenstein et al., 1992; Maglóczky and Freund, 1993). Neuronal loss in the hilar region is believed to be a trigger for the aberrant sprouting of mossy fibers (Tauck and Nadler, 1985).

Physiological patterns of neuronal activity depend on a critical balance of excitation and inhibition. In this respect, the hilar region has a special status. Its population consists of approximately equal proportions of principal cells, the so-called "mossy" cells (Amaral, 1978), and inhibitory interneurons (Seress and Ribak, 1983; Buckmaster and Jongen-Relo, 1999). This arrangement is quite distinct from other cortical areas, where principal cells substantially outnumber interneurons (Freund and Buzsáki, 1996). Mossy cells form a relatively homogeneous cell population, but hilar interneurons display remarkable morphological, neurochemical, and electrophysiological heterogeneity (Amaral, 1978; Han et al., 1993; Mott

\footnotetext{
Received April 18, 2000; revised June 19, 2000; accepted June 29, 2000.

This work was supported by National Institutes of Health (MH 54671), Howard Hughes Medical Institute, OTKA Hungary T 32251, the Bolyai János Scholarship, and Spanish DGES (PM97-0097). F.J.M.-G. was the recipient of a travel fellowship from the Spanish DGICYT. The mouse anti-CCK antibody was provided by the Cure Gastroenteric Biology Center, Antibody/RIA Core, National Institutes of Health Grant DK 41301. We are grateful to Dr. T Görcs for CCK, VIP, CGRP, and mGluR1a antibodies, as well as to R. Shigemoto for SPR, K. G. Baimbridge for rabbit anti-parvalbumin, K. Mackie for CB1, and C. Cozzari for CHAT antibodies. The technical assistance of Erzsébet Borók, Erzsébet Oszwald, and Gyozo Goda is gratefully acknowledged.

Correspondence should be addressed to Tamás Freund, Institute of Experimental Medicine, Hungarian Academy of Sciences, H-1450 Budapest, P.O.B. 67, Hungary. E-mail: freund@koki.hu.

Copyright (C) 2000 Society for Neuroscience $0270-6474 / 00 / 206907-13 \$ 15.00 / 0$
}

et al., 1997; Sík et al., 1997; Lubke et al., 1998). The main excitatory input of the hilus derives from the mossy fibers of granule cells (Blackstad and Kjaerheim, 1961; Amaral and Dent, 1981; Claiborne et al., 1986). Large mossy terminals innervate excitatory mossy cells (Ribak et al., 1985; Claiborne et al., 1986; Frotscher et al., 1991), whereas the more numerous small terminal types of the mossy fibers contact a larger number of interneurons (Acsády et al., 1998).

In contrast to excitatory inputs, GABAergic afferents to various hilar cell types have not been studied extensively (Hájos et al., 1996). In the hippocampus, the perisomatic region of excitatory and inhibitory cells is innervated by numerous GABAergic terminals (Freund and Buzsáki, 1996; Gulyás et al., 1999) that significantly affect firing characteristics. Perisomatic inhibition is critical in the timing of the action potential (Miles et al., 1996) and in the generation of various network rhythmic activities, including gamma frequency oscillations (Buzsáki and Chrobak, 1995; Cobb et al., 1995; Sík et al., 1995; Whittington et al., 1995; Ylinen et al., 1995; Wang and Buzsáki, 1996; Tóth et al., 1997a; Penttonen et al., 1998). Because the power of gamma oscillation is largest in the hilar region in vivo (Buzsáki et al., 1983; Bragin et al., 1995a), the issue of perisomatic inhibition in the hilus is of particular interest.

In the dentate gyrus and hippocampal CA1-CA3 regions with compact cell layers, somatic and proximal dendritic inhibition derives from two main basket cell populations (perisomatic inhibitory cells) that differ in their local and subcortical inputs, transmitter receptors, and neuropeptide content (Freund and Buzsáki, 1996). One of them contains parvalbumin (Kosaka et al., 1987), whereas the other colocalizes cholecystokinin (CCK) (Nunzi et al., 1985) and vasoactive intestinal polypeptide (VIP) (Acsády et al., 1996a,b). Although the hilar region also contains these neuron types, it is not known whether they also target the perisomatic domain of mossy cells and interneurons. In the present study we aimed to identify the postsynaptic targets of parvalbumin- and CCK-positive interneurons in the hilar region, with special reference to the perisomatic regions of the innervated cells. 


\section{MATERIALS AND METHODS}

Twenty-three adult male Wistar rats (Charles River, Budapest, Hungary) were used. All experimental procedures were performed according to the ethical guidelines of the Institute of Experimental Medicine, Hungarian Academy of Sciences and approved by the Ethical Committee. Sixteen rats were perfused under deep Equithesin (chlornembutal, $0.3 \mathrm{ml} / 100 \mathrm{gm}$ ) anesthesia without prior surgery. Three different fixatives were used to optimize the immunostaining with various antibodies and their combinations. In eight rats the physiological saline $(1 \mathrm{~min})$ was followed by $400 \mathrm{~m}$ of fixative containing $0.05 \%$ glutaraldehyde, $4 \%$ paraformaldehyde, and $0.2 \%$ picric acid in $0.1 \mathrm{~m}$ phosphate buffer ( $\mathrm{PB} ; \mathrm{pH} 7.4$ ) for $30 \mathrm{~min}$ (fixative A, our routine fixation protocol). For CCK immunostaining, five rats were perfused with $80 \mathrm{ml}$ fixative containing $3.75 \%$ acrolein and $2 \%$ paraformaldehyde ( $5 \mathrm{~min}$ ) in $0.1 \mathrm{M} \mathrm{PB}$ and then with $300 \mathrm{ml} 2 \%$ paraformaldehyde in $0.1 \mathrm{M} \mathrm{PB}$ (fixative B). In three rats the saline was followed by $400 \mathrm{ml}$ of fixative containing $2 \%$ paraformaldehyde in $0.1 \mathrm{M} \mathrm{PB}, \mathrm{pH} 7.4$, for $30 \mathrm{~min}$ (fixative C, "weak fixation" protocol for parvalbumin immunostaining).

To enhance immunostaining for calcitonin gene-related peptide (CGRP) (Freund et al., 1997), in three additional rats a total volume of $8-15 \mu \mathrm{l}$ of colchicine $(1 \mathrm{mg} /$ in $100 \mu \mathrm{l}$ saline) was injected by pressure through a glass capillary bilaterally into the lateral ventricle under deep Equithesin anesthesia (chlornembutal, $0.3 \mathrm{ml} / 100 \mathrm{gm}$ ). The coordinates were the following: $1.0-1.2 \mathrm{~mm}$ posterior to the Bregma, $1.5-1.8 \mathrm{~mm}$ lateral to the sagittal sinus, and $3.0-3.5 \mathrm{~mm}$ below the pial surface. One day after the operation the animals were anesthetized again with Equithesin and perfused with fixative A.

In four rats, fimbria-fornix lesion (FFX) was made to remove GABAergic septohippocampal afferents that contain parvalbumin (Freund, 1989). The cingulate cortex $(\sim 2 \mathrm{~mm}$ wide gap), the cingulate bundle, the corpus callosum, dorsal fornix, fimbria, and ventral hippocampal commissure were removed by aspiration. Four days after the operation the animals were anesthetized again with Equithesin and perfused with fixative A.

After perfusions, coronal or horizontal sections (60 $\mu \mathrm{m}$ thick) were cut from the hippocampus on a Vibratome, washed, cryoprotected in $30 \%$ sucrose in $0.1 \mathrm{M} \mathrm{PB}$ overnight, and freeze-thawed in an aluminum foil boat over liquid nitrogen. After extensive washes and treatment with $1 \%$ sodium borohydride for 30 min (only for animals fixed with fixative B), the sections were incubated in the following antisera. For single or as a first immunostaining, rabbit anti-CCK (1:6000) (Gulyás et al., 1990), rabbit anti-parvalbumin (1:4000) (Baimbridge and Miller, 1982), or mouse antiparvalbumin (1:1000) (Sigma Immuno Chemicals, St. Louis MO), or rabbit anti-VIP (1:10000) (Gulyás et al., 1990) or rabbit anti-CGRP $(1: 10,000)$ (Baffi et al., 1992) or CB1 cannabinoid receptor (1:1000, Tsou et al., 1999) were used for $2 \mathrm{~d}$ at $4^{\circ} \mathrm{C}$. In case of the FFX animals, the completeness of the lesion was checked using mouse anti-choline acetyl transferase antibody (CHAT; 1:300) (Cozzari et al., 1990). The specificity of the antibodies was studied extensively by the laboratories of origin. To enhance the penetration of the parvalbumin antibodies, some of the sections treated with parvalbumin antisera were incubated for $5 \mathrm{~d}$ at room temperature with $1 \%$ Triton X-100 (Sigma Immuno Chemicals), and $\mathrm{NaN}_{3}$ was added to the solution.

The second layer was biotinylated anti-rabbit $\operatorname{IgG}$ made in goat or biotinylated anti-mouse IgG made in horse (Vector Laboratories, Burlingame, CA) $(1: 300,2 \mathrm{hr})$ followed by avidin biotinylated-horseradish peroxidase complex (ABC, Vector Laboratories) (1:300, $1.5 \mathrm{hr}$ ). All of the washes and dilutions of antisera were performed in $0.05 \mathrm{M}$ Tris buffered saline (TBS), pH 7.4. The immunoperoxidase reaction was developed with ammonium nickel sulfate-intensified 3,3'-diaminobenzidine (DAB) as a chromogen. The sections were treated with $1 \% \mathrm{OsO}_{4}$ in $0.1 \mathrm{M} \mathrm{PB}$ for 45 min, dehydrated in ethanol and propylene oxide, and embedded in Durcupan (ACM, Fluka, Buchs, Switzerland). During dehydration the sections were treated with $1 \%$ uranyl acetate in $70 \%$ ethanol for $40 \mathrm{~min}$

For double immunostaining, the first immunoreaction was followed by one of the following antisera: rabbit anti-substance P receptor (SPR; 1:3000) (Shigemoto et al., 1993), rabbit anti-calretinin (1:5000) (Rogers, 1989), mouse anti-metabotropic glutamate receptor 1a (mGluR1a 1:10; gift of Dr. T. Görcs, Budapest, Hungary), rabbit anti-CGRP (1:10,000) (Baffi et al., 1992), anti-AMPA-type glutamate receptor 2/3 subunit (GluR2/3 1:100; Chemicon International Inc., Temecula, CA), or rabbit antiparvalbumin (1:2000). The second layer was biotinylated anti-rabbit $\operatorname{IgG}$ made in goat or biotinylated anti-mouse $\operatorname{IgG}$ made in horse (Vector Laboratories) (1:300, $2 \mathrm{hr}$ ) followed by ABC (Vector Laboratories) (1.5 hr, 1:300). The immunoperoxidase reaction was developed with $D A B$ as a chromogen, resulting in brown reaction product. Next the sections were treated with $1 \% \mathrm{OsO}_{4}$ (containing $7 \%$ glucose to preserve color difference) in $0.1 \mathrm{M}$ PB for $45 \mathrm{~min}$, dehydrated, and embedded in Durcupan (ACM, Fluka) as above. Correlated light and electron microscopy were used in 75 cases to verify the synaptic specialization between the labeled profiles. The ultrathin sections containing the identified contacts were examined by a Hitachi-7100 electron microscope. In several cases, profiles labeled by $\mathrm{DAB}$ and DAB-Ni were identified on the basis of color difference in the light microscope and then examined in the electron microscope. In these correlated light and electron microscopic samples, we confirmed that the two types of end product can be distinguished also in the electron microscope; the DAB-Ni precipitate was always more electron dense and inhomogeneous compared with DAB (see Figs. 4, 7, 8).

The axons of CCK-immunoreactive cells were reconstructed with a drawing tube from serial $60-\mu \mathrm{m}$-thick sections immunostained for CCK. CCK immunoreactivity poorly visualizes dendritic processes. Thus, reconstruction of the dendritic trees of CCK-immunoreactive neurons was made from consecutive CCK-SPR double-stained sections, because SPR reveals the dendrites in great details, unlike CCK, and is expressed in all CCKpositive neurons (Acsády et al., 1997). Light microscopic quantification of terminals around cell bodies was performed using a $100 \times$ oil immersion objective. Only terminals attached to the somatic surface of the neurons were considered; contacts on proximal dendrites were excluded from this analysis.

To study the coexistence of CCK with VIP, the mirror technique of Kosaka et al. (1985) was used, extended to cells having one or several main dendrites cut on the surface as described previously (Acsády et al., 1996a). Thus, three consecutive sections were reacted for CCK-SPR, and the fourth was reacted for VIP. The continuation of cut dendrites was identified on the common surfaces of adjacent sections using capillaries as landmarks.

For fluorescent double immunostaining the following mixture of antisera was used: mouse anti-CCK (1:2000) (provided by Cure/Gastroenteric Biology Center, Los Angeles, CA) and rabbit anti-VIP (1:5000). The second layer was lissamine rhodamine-conjugated anti-mouse IgG made in goat (1:100) (Jackson ImmunoResearch, West Grove, PA) and Alexa 488-conjugated anti-rabbit IgG made in goat (1:200) (Molecular Probes, Eugene, OR) or Cy3-conjugated donkey anti-rabbit (1:200) (Jackson ImmunoResearch) and FITC-conjugated goat anti-mouse IgG (1:100) (Jackson ImmunoResearch). The sections were examined in a Zeiss Axioplan2 fluorescent microscope using Zeiss Filter set 10 (excitation BP 450-490; emission BP 515-565) and Filter set 15 (excitation BP 546/12; emission LP 590).

The color version of certain double immunostainings is available as supplementary information at the following worldwide web page: http://www. koki.hu/ Acsády/hilus.

\section{RESULTS}

\section{Axonal and dendritic arborization of CCK-immunoreactive interneurons}

The distribution of CCK-immunoreactive neurons in the dentate gyrus was similar to that described earlier (Somogyi et al., 1984; Kosaka et al., 1985; Nunzi et al., 1985; Léránth and Frotscher, 1986; Sloviter and Nilaver, 1987). Briefly, round, ovoid, or fusiform CCK-containing cell bodies of various sizes were scattered in the hilus, whereas at the stratum (str.) granulosum/hilus border, CCKpositive cells had a pyramidal shape with apical dendritic tufts crossing str. moleculare. More than two-thirds of the CCK-positive neurons $(68.7 \%, n=147)$ were located in the hilus, whereas the rest belonged mainly to the type with pyramidal shape. As in earlier studies, two prominent types of CCK-immunoreactive fibers were observed. One of them displayed large axonal swellings and formed pericellular baskets around immunonegative cells in the hilus with up to 20-25 boutons per cell. The other fiber type arborized most extensively in the str. granulosum and in the supragranular layer with somewhat smaller terminals. CCKpositive varicosities were rare in the outer str. moleculare.

To examine whether the two CCK-positive fiber types originate from CCK-containing interneurons in the hilus and str. granulosum, respectively, we reconstructed the axonal and dendritic arbors of various CCK-immunoreactive neurons. Reconstructions of the dendritic trees were made from CCK-SPR double-stained sections because SPR reveals the dendrites in great detail and is expressed in all CCK-positive neurons (Acsády et al., 1997). CCK-immunoreactive neurons in the hilus were bitufted or multipolar and had four to six smooth, thick, primary dendrites that frequently ran parallel to str. granulosum and branched distally from the cell body (Fig. 1). The majority of the dendritic tree was confined to the hilus and only rarely reached str. radiatum of the $\mathrm{CA} 3 \mathrm{c}$ region. Hilar CCK-positive cells always had one to three dendrites that penetrated str. granulosum and branched in str. moleculare (Fig. 1). The pyramidal-shaped CCK-positive cells in str. granulosum had a thick apical dendrite that split into several thin secondary dendrites on reaching the upper limit of str. granulosum and extended into str. moleculare with "graceful arch" (Amaral, 1978). Secondary dendrites frequently ran parallel with the laminar boundaries and remained in the inner third or str. granulosum. Most of these dendrites were very thin, occasionally beaded, and rarely ramified. In str. moleculare, thin, thread-like connections were occasionally observed among the dendrites of different CCK-positive cells sim- 

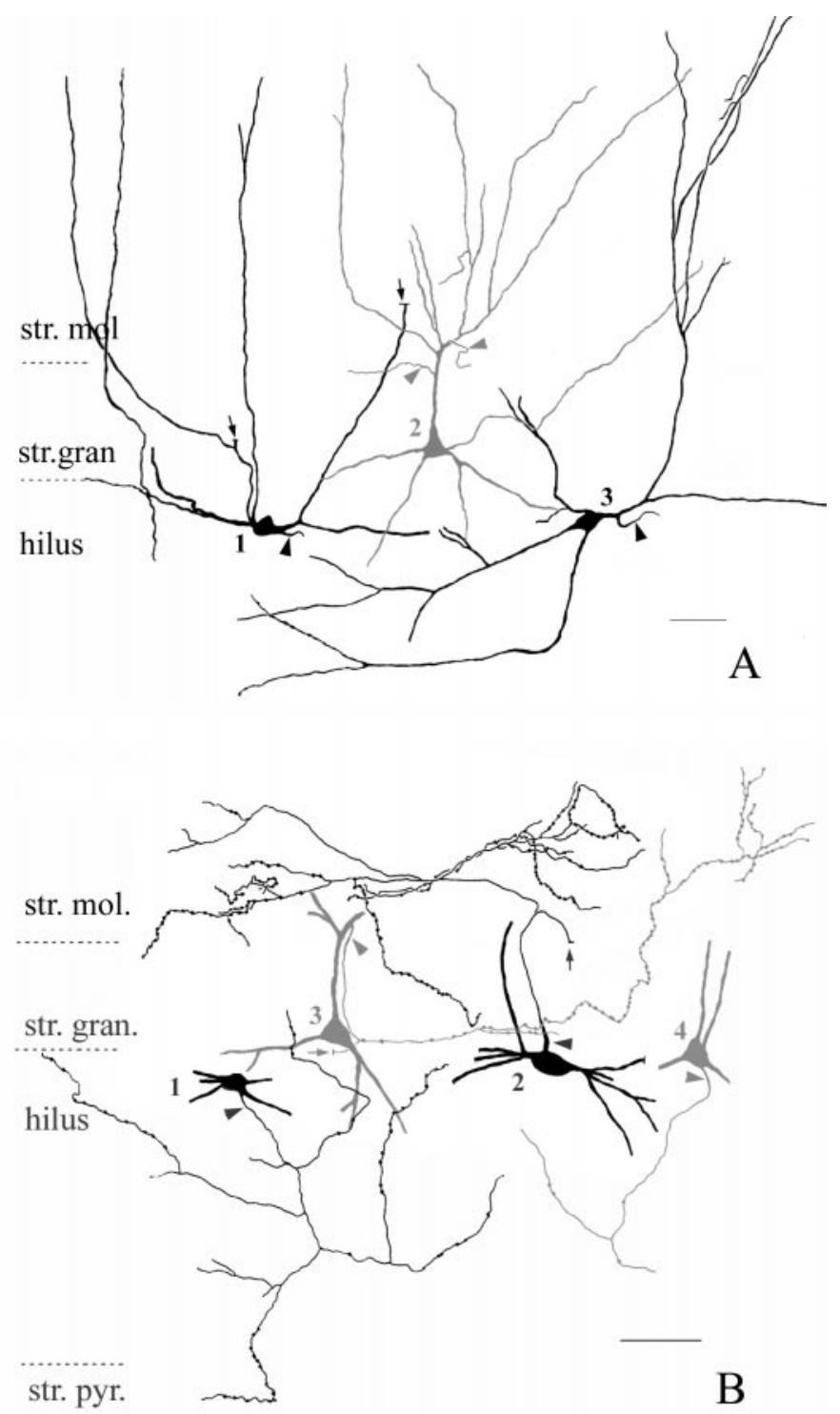

Figure 1. Camera lucida drawings of the dendritic branching pattern $(A)$ and the proximal axonal arbor $(B)$ of CCK-positive interneurons in the dentate gyrus. The reconstructions were made from consecutive $60-\mu \mathrm{m}-$ thick sections immunostained for CCK and SPR in $A$ (see Materials and Methods) and for CCK in B. A, Hilar fusiform (cells 1 and 3, black) and pyramidal-like (cell 2, dark gray) CCK-positive interneurons are shown. Both cell types extend dendrites into str. moleculare as well as into the hilus. Note the prominent apical tuft of the pyramidal-like cell. Arrows point to dendrites that were used to establish that cell 1 is negative for VIP in "mirror" sections (see Materials and Methods). Arrowheads indicate axon initial segments. Scale bar, $40 \mu \mathrm{m}$. B, Proximal axon arbor of fusiform (cells 1 and 2, black) and pyramidal-like (cells 2 and 4, dark gray) CCK-positive interneurons in the dentate gyrus. The axon terminals of both cell types innervate the supragranular str. moleculare as well as the hilus. The axon of cell 1 reaches str. pyramidale of the CA3c region. Arrows point to thick, proximal axon segments that faded abruptly within the section, a sign of myelination. Arrowheads indicate axon initial segments. Scale bar, $50 \mu \mathrm{m}$.

ilar to that described among other GABAergic cells (Katsumaru et al., 1988; Hájos et al., 1998). The basal dendrites of pyramidal-like CCK-positive cells were confined to the hilus.

Some small, round CCK-immunoreactive cells, mainly in str. moleculare, contain VIP (Hájos et al., 1996). Using double immunofluorescent methods, we established that the vast majority (118 of 124 neuron) of pyramidal-like $(n=40)$ and hilar fusiform $(n=$ 78) CCK-immunoreactive cells are negative for VIP (data not shown), which was also confirmed using the mirror technique $(n=$ 5) (Fig. 1). The remaining six cells as well as seven additional small, round CCK-positive neurons in str. moleculare colocalized VIP as shown in earlier studies (Hájos et al., 1996). In the CCK/VIP double immunofluorescent sections, brightly fluorescent doubleimmunostained fibers with large boutons were seen in str. granulosum but not in str. moleculare. As described before (Hájos et al.,. 1996) in VIP-immunostained material, these fibers occurred in patches rather than homogeneously covering the entire str. granulosum. CCK-positive fibers in the inner str. moleculare were homogeneous along the dentate gyrus and had smaller boutons. These features suggest that the majority of these fibers originate from the VIP-negative CCK-immunoreactive interneuron population.

The quality of immunostaining allowed us to reconstruct the proximal part of the axonal arbor of various CCK-immunoreactive cells. We found that there was no correlation between the location of CCK-positive somata and their projection pattern. Thus, the axons of hilar fusiform cells as well as those of pyramidal-shaped neurons were found to ramify either in str. moleculare or the hilus, or both (Fig. 1). In addition, the axon of a single cell was found to reach str. pyramidale of the CA3c region as well.

Our conclusion is that despite their morphological heterogeneity, CCK-immunoreactive cells appear to form a functionally homogeneous cell population in the hilar region. They pick up excitatory input via their dendrites in the hilus as well as in str. moleculare (although the ratio of granule cell vs entorhinal cortical input might be different for hilar vs pyramidal-like cells) and project to both of these regions.

\section{Target selectivity of CCK-immunoreactive axon terminals in the hilus}

Recent advances in chemical neuroanatomy identified several neurochemical markers that allow the visualization of distinct hilar cell types. In the present study, mossy cells were visualized by immunostaining for GluR2/3 and CGRP (Léránth et al., 1996; Freund et al., 1997). To characterize CCK input to the heterogeneous hilar GABAergic cell population, we selected antibodies that label interneurons from each of the three major interneuron types classified according to their axonal arborization pattern and target selectivity. Interneurons with axonal arbors innervating the perisomatic region of principal cells and other interneurons (perisomatic inhibitory cells) were visualized by parvalbumin and CCK. The best characterized hilar cell population, the somatostatincontaining hilar-perforant path-associated (HIPP) cells (Baude et al., 1993; Han et al., 1993; Katona et al., 1999a) that arborize in the dendritic region of granule cells (dendritic inhibitory cells), was visualized by mGluR1a. GABAergic cells that are specialized to contact other GABAergic cells (interneuron-selective cells) were labeled by an antiserum against calretinin (Freund and Buzsáki, 1996; Gulyás et al., 1996). In addition, a large hilar GABAergic cell population that includes a portion of perisomatic, dendritic, and interneuron selective inhibitory cells was identified by its SPR immunoreactivity (Acsády et al., 1997).

\section{Innervation of mossy cells}

The pattern of GluR2/3 immunostaining was identical to that described earlier (Léránth et al., 1996). Briefly, large ovoid or triangular cell bodies were labeled in the hilus together with the proximal segment of their two or three main dendrites. The principal cells of other hippocampal regions were also labeled. In CCK-GluR2/3 double-immunostained sections, CCK-immunoreactive terminals surrounded nearly all GluR2/3-immunoreactive neurons, their somata, and their proximal dendrites in a basket-like manner in the dorsal as well as in the ventral hippocampus (Figs. $2 A, 3 A)$. Arrays of CCK-positive terminals around GluR2/3negative cell bodies were found only very rarely. The density of CCK-positive boutons around mossy cells never approached that around pyramidal cells in the CA1 and CA 3 regions. The relatively low packing density of GluR2/3-immunoreactive cells and the reasonable penetration of the CCK-positive terminals allowed us to quantify the number of CCK-containing axonal swellings around mossy cell bodies at the light microscopic level. On average, 10.3 CCK-positive terminals contacted the somata of GluR2/3-positive 

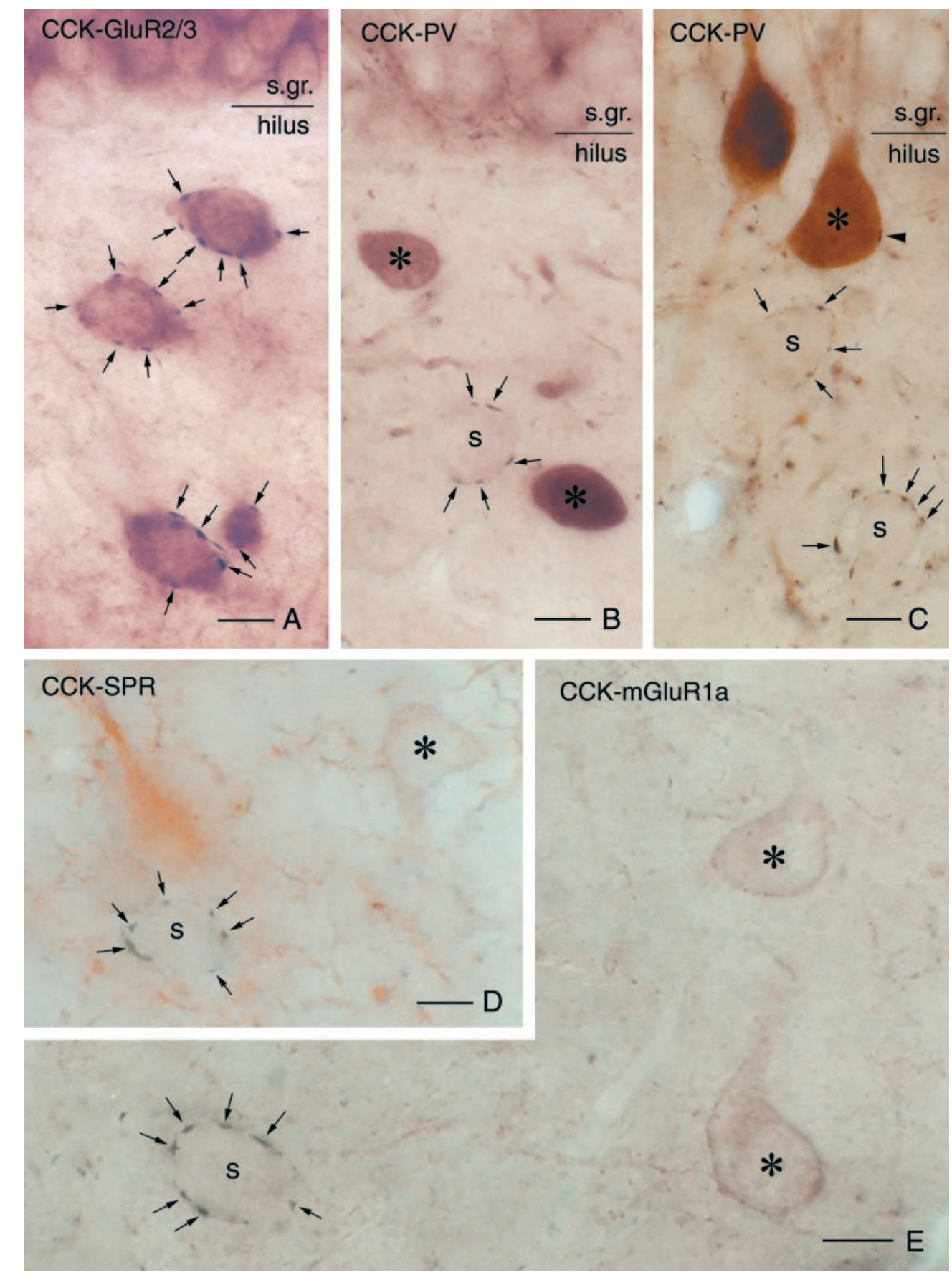

Figure 2. Target selectivity of CCKimmunoreactive terminals in the hilus. $A$, High-power light micrograph of a double-immunostained section demonstrates that several CCK-positive terminals (arrows, black chromogene) contact GluR2/3-positive mossy cells (brown chromogene) in a basket-like manner. $B-E$, In contrast, CCK-positive pericellular baskets (arrows) never surround the cell bodies (asterisks) of various interneuron classes visualized by parvalbumin $(B, C)$, SPR $(D)$, or mGluRla $(E)$. In these sections, multiple perisomatic contacts can always be seen around immunonegative, presumed mossy cells $(S)$. Arrowhead in $C$ indicates a single CCK-positive contact on a parvalbuminimmunoreactive cell. Scale bars, $10 \mu \mathrm{m}$. neurons $(n=100$ cell; SEM $=0.34)$. Because GluR2/3 immunostaining may label a few interneurons as well, we repeated the experiment using a more specific mossy cell marker, CGRP. CGRP immunostaining labeled large numbers of mossy cells mainly in the temporal part of the hippocampus in colchicine-treated animals together with their termination zone in the inner third of str. moleculare, as described previously (Freund et al., 1997). Colchicine treatment did not alter the distribution of CCK-positive elements. The CCK-CGRP double staining gave essentially the same results as $\mathrm{CCK}-\mathrm{GluR2/3}$ immunostaining. CCK-positive terminals contacted all CGRP-containing cell bodies and proximal dendrites. On average, CGRP-positive cell bodies were surrounded by 9.9 CCK-containing terminals $(n=50$ cell bodies; SEM $=0.44)$. The number of CCK-positive contacts around CGRP- and GluR2/3imunoreactive cells was statistically similar ( $t$ test, $p>0.1$ ).

The CCK input to CGRP-positive neurons was confirmed using the mirror technique, which excludes potential false CGRP immu- noreactivity in the postsynaptic targets. In adjacent CCK- and CGRP-immunostained sections, the other half of nearly all CGRPcontaining cell bodies (30 of 34) identified in the CCK-immunostained sections was surrounded by CCK-positive terminals.

To reveal whether the light-microscopically identified CCKpositive terminals correspond to conventional synaptic boutons, representative samples of CCK-GluR2/3 $(n=21)$ and CCK-CGRP $(n=20)$ contacts were examined by correlated light and electron microscopy. All 41 terminals formed symmetric synaptic specializations on the somata or proximal dendrites of GluR2/3- or CGRP-labeled mossy cells (Fig. 4). The electron microscopic examination did not reveal more CCK-positive terminals than established by light microscopy. The size of the elongated boutons was highly variable, (minor axis $0.5-1 \mu \mathrm{m}$, major axis $1.5-3 \mu \mathrm{m}$ ), and they contained few mitochondria. Nearly all of them had long synaptic active zones that were often disjunct or perforated (Fig. 4). Occasionally the two halves of a perforated synapse were 

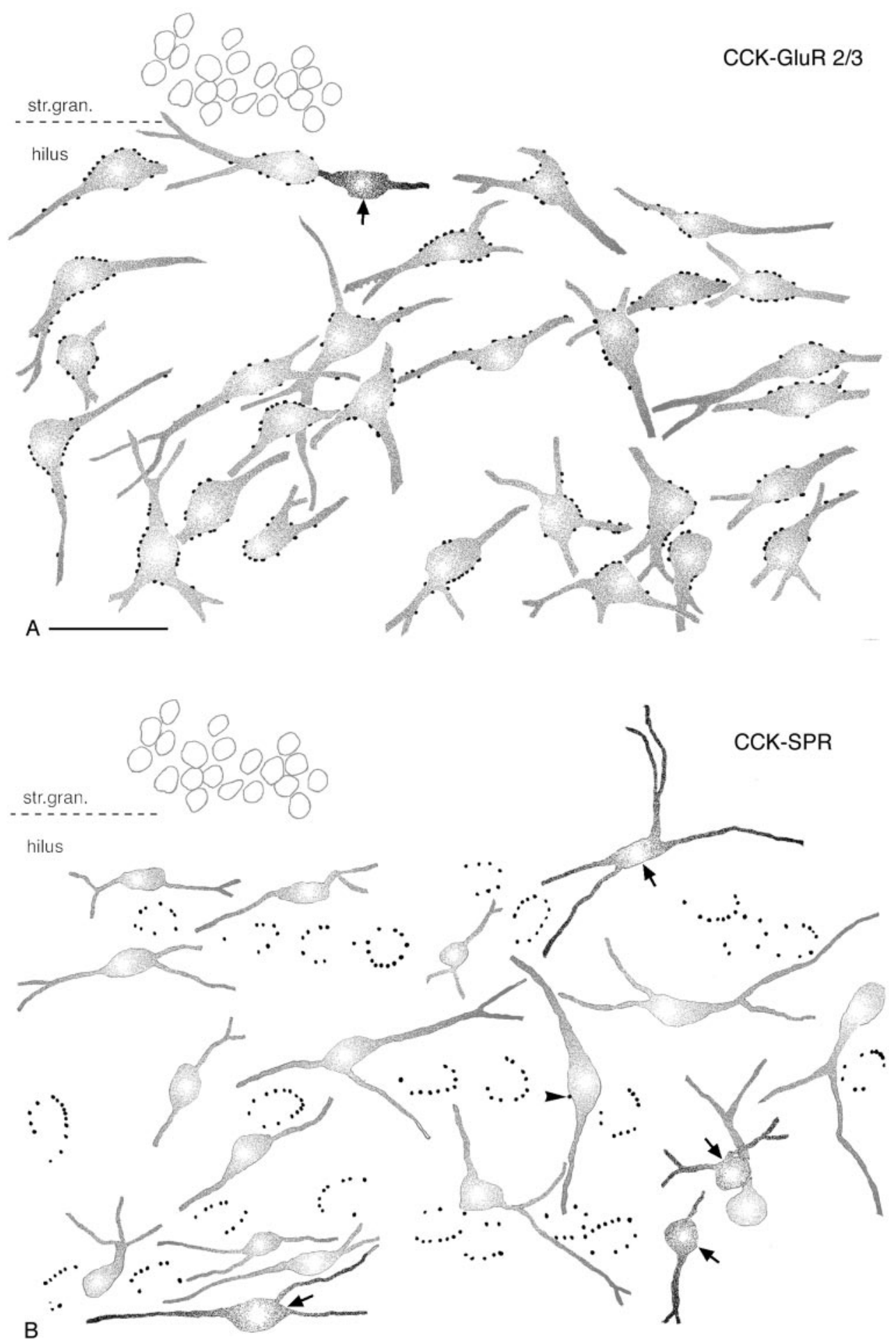

Figure 3. CCK-immunoreactive terminals selectively innervate mossy cells in the hilar region. Camera lucida drawings are of CCK-GluR2/3 and CCK-SPR doubleimmunostained sections. A, Several CCKimmunoreactive terminals surround the somata and proximal dendrites of each GluR2/3-positive neuron. $B$, In contrast, none of the SPR-containing interneurons are contacted by multiple CCK-positive boutons. Arrows in $A$ and $B$ indicate CCKpositive neurons that are avoided by CCKimmunoreactive terminals, similar to other GABAergic cells. Arrowhead in $B$ points to a single CCK-positive contact on an SPRexpressing interneuron. Scale bar (shown in $A$ for $A$ and $B$ ): $50 \mu \mathrm{m}$. separated by a protrusion from the presynaptic terminal, which deeply invaginated into the postsynaptic profile as shown previously (Léránth and Frotscher, 1986).

\section{Innervation of interneurons}

First we examined the connections among CCK-containing basket cells. CCK-containing terminals arranged in a basket-like manner were never found around CCK-immunoreactive interneurons; $80 \%$ of the cells received no contacts at all (Fig. 3). At the light microscopic level, CCK-positive cells were surrounded, on average, by 0.2 terminals $(n=100$ cell bodies; SEM $=0.05)$.

Subsequently we examined the CCK input to parvalbuminpositive perisomatic inhibitory cells and to mGluR1a-positive den- dritic inhibitory cells (HIPP cells). The pattern of parvalbumin and mGluR1a immunostaining was similar to that published earlier (Kosaka et al., 1987; Baude et al., 1993). The dendrites and somata of large ovoid hilar neurons covered with long thin spines were labeled for mGluR1a. The entire dendritic arbor of mGluR1apositive neurons was confined to the hilus. Parvalbumin immunostaining is described in detail in the next section.

In the case of CCK-parvalbumin double-immunostained sections, the staining was optimized for CCK-positive axons (see Materials and Methods); thus parvalbumin-positive boutons were weak on the surface and absent deeper than 2-3 $\mu \mathrm{m}$ below the surface of the sections. Basket-like multiple CCK-immunoreactive 

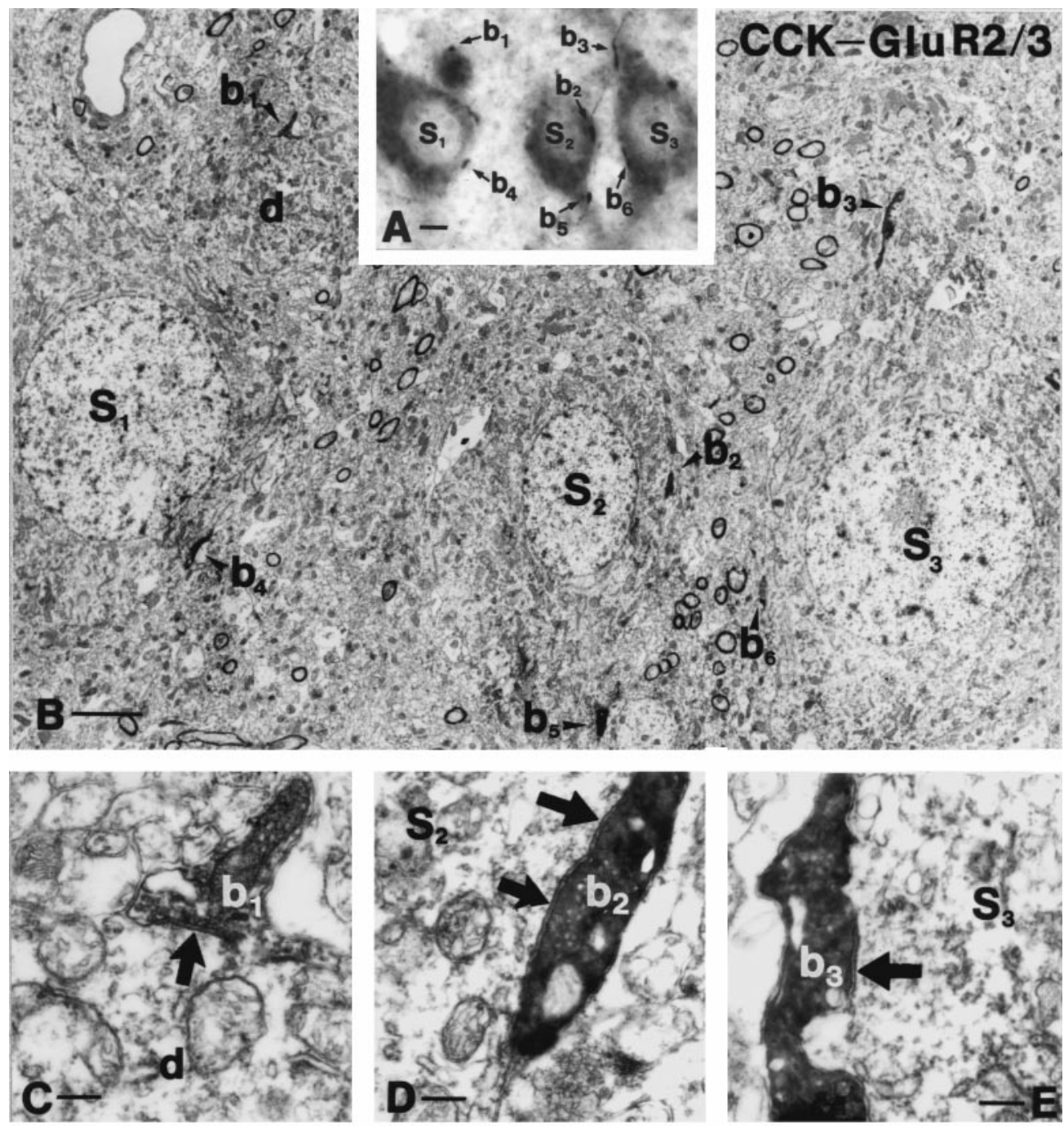

Figure 4. Correlated light and electron micrographs of GluR2/3-immunoreactive mossy cells $\left(S_{1}-S_{3}\right)$ receiving multiple contacts from CCK-positive boutons $\left(b_{1}-\right.$ $\left.b_{6}\right)$. The low-power $(B)$ and high-power micrographs $(C-H)$ verify that conventional symmetrical synapses are established on the somata $\left(b_{2}, b_{4}, b_{6}\right)$ and proximal dendrites $\left(b_{1}, \boldsymbol{b}_{3}, b_{5}\right)$ of mossy cells (arrows). Note the long $(D)$ or perforated $(F, G)$ postsynaptic specializations of synapses formed by CCK-positive terminals. Scale bars: $A, 6 \mu \mathrm{m} ; B, 3 \mu \mathrm{m} ; C, 0.4 \mu \mathrm{m}$.
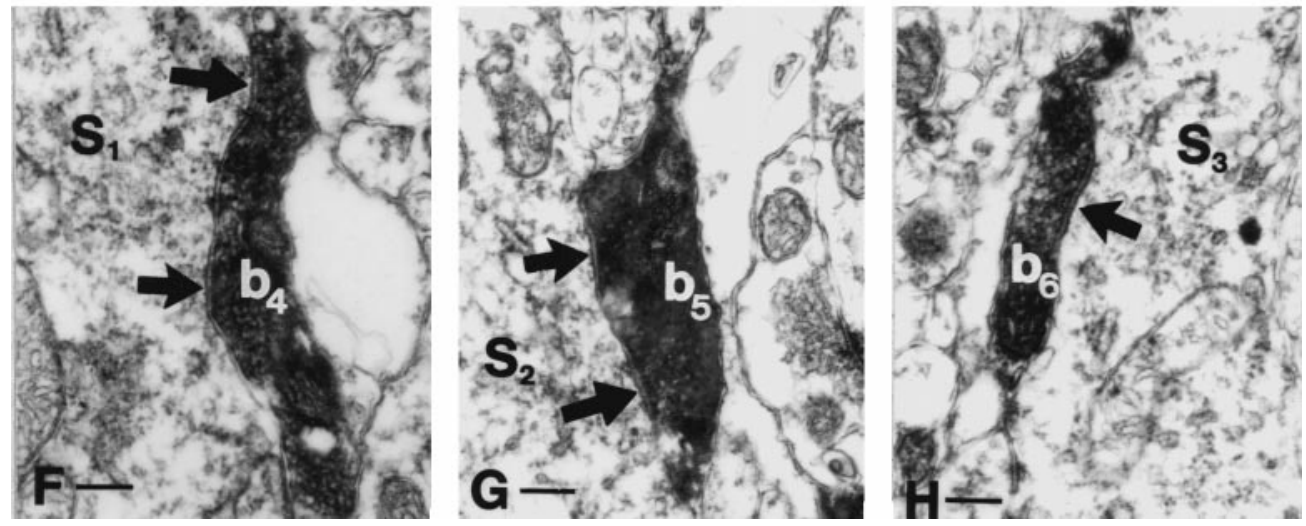

contacts were found only around parvalbumin-negative cell bodies (Fig. $2 B, C$ ). Seventy-nine percent of the parvalbumin-containing interneurons received no CCK-positive terminals at all. In the rest of the cases the number of contacts was limited to one, two, or rarely three. Similarly, mGluR1a-containing interneurons were always avoided by perisomatic arrays of CCK-positive terminals (Fig. $2 E)$. A small portion $(10 \%)$ of the cells received one or two CCK terminals. The average number of CCK-positive boutons per cell body counted at the light microscopic level was $0.4(n=100$; $\mathrm{SEM}=0.09)$ in the case of parvalbumin-containing interneurons and 0.2 in the case of mGluR1a-containing interneurons $(n=100$; SEM = 0.07). CCK-positive terminals on parvalbumin- or mGluR1a-immunoreactive dendrites were found only occasionally, and they always involved only a single terminal. To check the quality of CCK immunostaining in these sections, we counted the number of terminals around parvalbumin- and mGluR1a-negative cell bodies as well. The results showed that the number of terminals around immunonegative cell bodies $(11.1, n=21$; $\mathrm{SEM}=0.64)$ was similar to that established in the CCK-GluR2/3 and CCKCGRP double-stained material.

The target selectivity of CCK-positive terminals in the hilus was further examined with double staining for calretinin and for SPR. Calretinin labels a GABAergic neuron population that selectively innervates other interneurons, the so-called interneuron-selective cells (Gulyás et al., 1996; Hájos et al., 1996), whereas SPR is expressed in a large, heterogeneous GABAergic cell population 
that includes all CCK-positive interneurons, more than two-thirds of the somatostatin-containing cells and one-third of the calretinincontaining cells and other uncharacterized interneuron populations (Acsády et al., 1997). The patterns of immunostaining for both antigens were identical to that published earlier. Numerous spiny and aspiny cells were revealed in the hilus. Double immunostaining for CCK and calretinin or for CCK and SPR demonstrated that similar to the other GABAergic cell populations, calretinin- or SPR-immunoreactive interneurons were not contacted by perisomatic arrays of CCK-positive terminals (Fig. 2D). The results were particularly striking in the case of CCK-SPR staining. Despite the fact that the hilus is relatively densely packed with SPR-containing interneurons, CCK-positive terminals always surrounded SPRnegative cell bodies (Fig. $3 B$ ).

An independent confirmation of the target selectivity of CCKimmunoreactive cells derived from CB1 cannabinoid receptor immunostaining. Previous studies demonstrated that $90 \%$ of the CCK-immunoreactive cells also contain CB1 (Katona et al., 1999b; Tsou et al., 1999), and similar to CCK immunostaining, large CB1-containing terminals form pericellular baskets in the hilus. In CB1-SPR and CB1-parvalbumin double-stained sections, large CB1-expressing terminals never surrounded parvalbuminor SPR-immunoreactive interneurons (data not illustrated).

Our conclusion is that CCK-immunoreactive cells display a striking target selectivity in the hilar region. They innervate mossy cells with multiple perisomatic synaptic contacts but largely avoid hilar GABAergic neurons (Fig. 5).

\section{Parvalbumin-immunoreactive neurons in the dentate gyrus}

Parvalbumin-immunoreactive neurons were present in the hilus as well as in str. granulosum of the dentate gyrus as described previously (Kosaka et al., 1987; Nitsch et al., 1990; Ribak et al., 1990). For the purpose of the present study, a parvalbumin-immunoreactive neuron will be considered as hilar if its cell body is clearly situated outside str. granulosum. In our sample, $58 \%$ of the parvalbumin-positive cells was found in the hilus $(n=176)$, whereas the rest were embedded in the granule cell layer. Hilar parvalbumin-immunoreactive neurons had large multipolar cell bodies with three to five thick primary dendrites. Many cells had one or two main dendrites that crossed str. granulosum and reached the outer third of str. moleculare. Most of the parvalbumin-containing cells in str. granulosum had pyramidal-shaped or ovoid cell bodies. In contrast to pyramidal-like CCK-positive cells, the dendrites of these parvalbumin-positive neurons did not split into thin secondary dendrites at the border of str. granulosum and moleculare, but thick secondary branches were emitted sequentially and followed a straight course as shown previously (Sík et al., 1997).

In contrast to the numerous descriptions of parvalbumin-positive axons in all other regions of the hippocampus, parvalbuminimmunoreactive axons in the hilus have been described as "almost absent" (Nitsch et al., 1990) or "few if any" (Ribak et al., 1990) or "restricted to the granule cell layer" (Kosaka et al., 1987). Most probably this can be attributed to the poor penetration of parvalbumin antisera in this region, as well as the relative scarcity of innervation compared with the dense parvalbumin-positive fiber plexi in the somatic layers of other hippocampal subfields. By using weak fixation or prolonged treatment of the sections in Triton (see Materials and Methods) many axonal processes could be visualized in the hilus (Fig. 6). Several of them crossed the hilus with only a few small en passant terminals, but in addition, parvalbuminimmunoreactive terminals arranged in a basket-like manner were also frequently found. In agreement with earlier studies, numerous parvalbumin-positive terminals were observed in str. granulosum and in the inner third of the molecular layer.

\section{Postsynaptic targets of parvalbumin-positive axons in the hilar region}

Only a limited number of antibodies work reliably under the conditions that allow the visualization of parvalbumin-positive


Figure 5. Bar graphs showing the number of CCK-positive $(A)$ and parvalbumin-positive $(B)$ terminals around the somata of interneurons $[I N T(L)$, black bars] and mossy cells $[\operatorname{MOSS}(R)$, gray bars]. Note that most of the interneurons receive no CCK or parvalbumin contact, whereas most mossy cells are innervated by multiple contacts. In $A$, INT $(L)$ comprises the pooled data of CCK-PV, CCK-mGluR1a, and CCK-CCK innervation, whereas MOSS $(R)$ includes CCK-GluR2/3 and CCK-CGRP data. In $B$, $I N T(L)$ is based on parvalbumin-SPR immunostaining, and MOSS $(R)$ consists of parvalbumin-GluR2/3 double-immunostaining data.

axons. Thus, to examine the target selection of parvalbuminpositive cells, the GluR2/3 antibody was used to label mossy cells, whereas SPR immunostaining was used for the identification of interneurons. In addition, connections among parvalbumin-positive interneurons were also examined.

\section{Innervation of mossy cells}

In sections with reasonable penetration for parvalbumin, nearly all GluR2/3-immunoreactive neurons were found to be contacted by parvalbumin-positive terminals. The overwhelming majority of the cells received multiple innervation from 6-16 terminals attached to the somata and proximal dendrites of mossy cells (Fig. 7) (for a color picture, see supplementary information on the website mentioned earlier). The average number of contacts around the cell bodies was $7.4(n=130 ;$ SEM $=0.30)$. It should be stressed that the density of parvalbumin-positive terminals around mossy cells was much weaker than around the principal cells in other hippocampal regions. A representative sample of 28 parvalbumin-positive terminals in close apposition to mossy cells was examined by correlated light and electron microscopy. The vast majority of them (23 of 28) established symmetric synaptic specializations (Fig. 7), whereas in the remaining cases, poor ultrastructure (because of the weak fixation protocol; see Materials and Methods) precluded the unequivocal characterization of the junctional membranes. The 
Figure 6. Interaction among parvalbumin-immunoreactive cells in the dentate gyrus. $A$, Parvalbumin-positive terminals contact (arrowheads) a parvalbumin-containing neuron in the hilus. Arrow points to an axon that could be traced back to the parvalbumin-positive plexus in str. granulosum. $B$, Similar multiple contacts were observed in the fimbria-fornix-lesioned animals, indicating that these terminals have local origin. $C$, Parvalbumin-immunoreactive terminals in str. granulosum densely cover the somata and apical dendrites of pyramidal-like parvalbumin-positive basket cells. Scale bars, $10 \mu \mathrm{m}$.
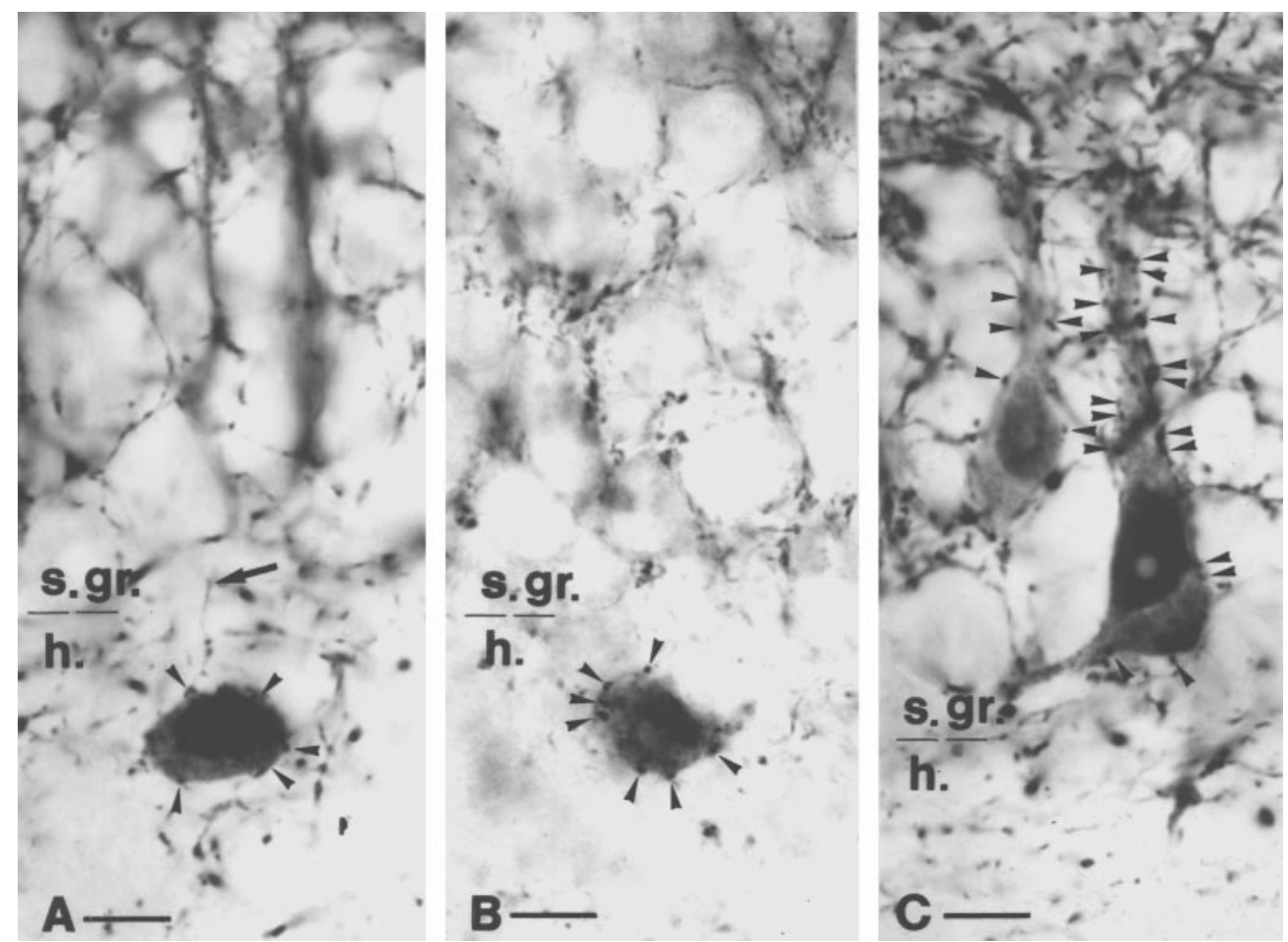

parvalbumin-containing terminals were round (diameter 1.5-2 $\mu \mathrm{m})$, always contained mitochondria, and in contrast to CCKpositive boutons, established synapses with a single active zone that was rarely perforated.

\section{Innervation of interneurons}

The connections among hilar parvalbumin-containing cells were examined in sections with prolonged Triton treatment (see Materials and Methods). Parvalbumin-immunoreactive terminals were frequently seen around parvalbumin-positive interneurons in the hilus (Fig. 6). The number of terminals was highly variable and could not always be unequivocally determined. Some of the cells received up to 10-15 terminals, whereas others were contacted by only three to five parvalbumin-positive boutons or received no contacts at all. Parvalbumin-positive cells in the hilus were in sharp contrast to those within the granule cell layer where the somata and the thick proximal dendrites of parvalbumin-containing interneurons were frequently surrounded by large numbers of parvalbuminpositive terminals (Fig. 6), as described before in the pyramidal cell layer of other hippocampal subfields (Fukuda et al., 1996; Gulyás et al., 1999). Those parvalbumin-immunoreactive cells that received a higher number of parvalbumin-positive terminals were situated just below str. granulosum, whereas those with fewer contacts resided more often in the deep hilus. Parvalbumin-positive axons that contacted parvalbumin-positive cells in the hilus could frequently be traced back to the fiber plexus in str. granulosum (Fig. 6A).

Parvalbumin-immunoreactive terminals innervated other hilar interneuron types very rarely (Fig. 5). In sections double-immunostained for parvalbumin and SPR, most of the parvalbumin-positive terminals arranged in a basket-like manner were around SPRnegative neurons (see supplementary information). Most of the SPR-immunoreactive cells $(75 \%, n=104)$ received no parvalbumin contacts at all; only four received more than three. The average number of parvalbumin-immunoreactive terminals around SPRpositive interneurons was 0.54 , which was statistically different (MannWhitney $U$ test, $p \gg 0.01$ ) from the number of parvalbumin-positive terminals contacting GluR2/3-expressing cells.

We also counted the number of parvalbumin-positive terminals around SPR-negative cell bodies. The average number of parvalbumin-immunoreactive terminals around SPR-negative cells
$(9.4, n=28)$ was similar to the number of parvalbumin-positive terminals around mossy cells (see above).

\section{Origin of parvalbumin-positive terminals in the dentate gyrus}

In addition to the local collaterals of hippocampal parvalbuminpositive basket cells, the hippocampus receives parvalbuminpositive fibers from the medial septum (Freund, 1989), which selectively innervates interneurons; among them quite frequently are parvalbumin-positive cells (Freund and Antal, 1988). To exclude the possibility that the observed hilar parvalbumin-parvalbumin contacts derive in large part from this subcortical center, parvalbumin-parvalbumin contacts were examined $4 \mathrm{~d}$ after fimbria-fornix lesion. Examination of the lesion site revealed complete removal of the fiber tract together with the overlying cortex, including the cingulate bundle. Immunostaining for CHAT demonstrated a nearly complete loss of CHAT-immunoreactive fibers from the hippocampus.

Many parvalbumin-parvalbumin contacts were found also in the fimbria-fornix-transected animals (Fig. 6B). The majority of these terminals showed no signs of degeneration. Occasionally, swollen parvalbumin-containing terminals were encountered climbing along parvalbumin-positive dendrites or somata. To compare the innervation of parvalbumin-positive cells by parvalbumin-containing axons in the lesioned and control animals, we calculated the proportion of parvalbumin-immunoreactive cells that received multiple (three or more) parvalbumin-positive contacts. In the control animals, 79.3\% of the parvalbumin-immunoreactive neurons were innervated by multiple parvalbumin-positive contacts $(n=92)$. This number did not change significantly after fimbria-fornix transection $(72.3 \%, n=$ 101). Thus, our conclusion is that most of the parvalbumin-positive terminals in the hilus belong to local collaterals of parvalbuminimmunoreactive basket cells. It should be emphasized, however, that parvalbumin-parvalbumin contacts were far more abundant in other subregions of the hippocampus than in the hilus.

\section{Interaction among interneurons in strata granulosum and moleculare}

As described above, the str. granulosum and the innermost part of str. moleculare contain dense plexi of CCK- and parvalbumin- 




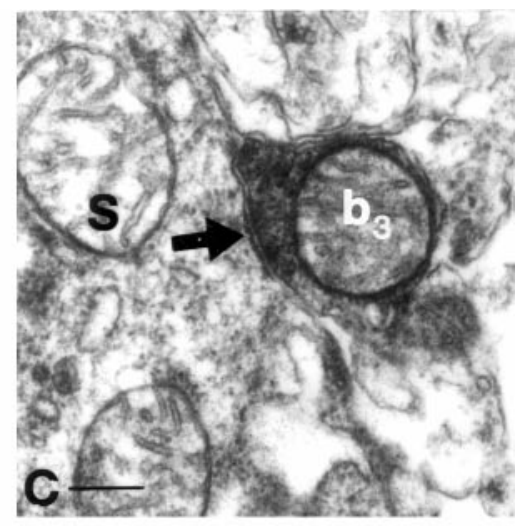
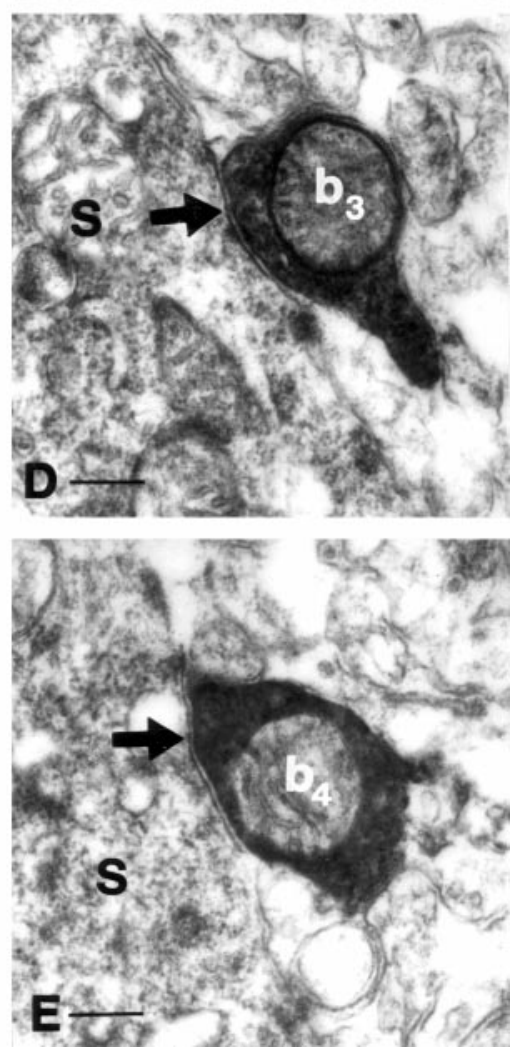

Figure 7. Innervation of mossy cells by parvalbumin-positive terminals. $A, B$, Correlated light and electron micrographs demonstrate that five parvalbumin-positive terminals $\left(\mathrm{b}_{1}-b_{5}\right)$ surround a GluR2/3positive interneuron in this focal plane. $C-E$, Two of these terminals $\left(b_{3}, b_{4}\right)$ are shown to establish symmetrical synapses on the somata of a mossy cell. These terminals rarely formed perforated synapses, e.g., see $b_{3}$ shown in two neighboring sections. Scale bars: $A, 20 \mu \mathrm{m} ; B, 2$ $\mu \mathrm{m} ; C, 0.5 \mu \mathrm{m}$. positive terminals. Because most of the hilar CCK- and parvalbumin-positive interneurons have dendrites in these layers, we examined the possibility that interneuron populations that largely avoid each other in the hilus may interact via their dendrites and axon collaterals in str. moleculare. In CCK-parvalbumin double-immunostained sections, CCK-positive terminals were frequently found to impinge on parvalbumin-immunoreactive dendrites, forming multiple contacts. Correlated light and electron microscopy revealed that in contrast to the hilus, small CCKpositive terminals $(<0.5 \mu \mathrm{m})$ established symmetrical synapses on thick proximal parvalbumin-positive dendrites in the inner molecular layer (Fig. 8) (for color version see supplementary information).

The interaction among CCK-positive neurons in the str. moleculare was examined in CCK-SPR double-immunostained sections to overcome the difficulties caused by the weak dendritic staining for CCK (see Materials and Methods). Because SPR immunostaining labels the dendrites and somata of all CCK-positive cells, the connections between CCK-positive terminals and CCK-SPRpositive dendrites could be examined and were found to be numerous. In addition to axo-dendritic and axo-somatic contacts, many CCK-SPR-positive dendrites frequently ran parallel to each other and formed multiple thin "bridges" with each other resembling rungs of a ladder similar to that described before in the case of m2-immunoreactive interneurons (Hájos et al., 1998) (data not shown).

In parvalbumin-SPR double-stained sections, many SPRimmunoreactive dendrites were contacted by parvalbumin-positive terminals, indicating an interaction among parvalbumin- and CCKpositive cells in str. moleculare. Parvalbumin-positive cells were found to innervate each other extensively in str. granulosum (Fig. $6 C$ ) as well as in str. moleculare, as described previously (Ribak et al., 1990). Thus, in contrast to the hilus, CCK- and parvalbuminpositive interneurons interact with each other in the inner molecular layer. HIPP cells have a dendritic tree restricted to the hilus. Thus, they could not be innervated by CCK- or parvalbuminpositive boutons in any other layer.

\section{DISCUSSION}

In this study we demonstrated that CCK- and parvalbuminimmunoreactive interneurons preferentially innervate mossy cells in the hilar region. The perisomatic innervation of hilar interneurons by these basket cells was found unusually sparse, whereas CCK- and parvalbumin-immunoreactive interneurons mutually innervated each other in strata granulosum and moleculare (Fig. 9). These findings indicate that interactions among the GABAergic 


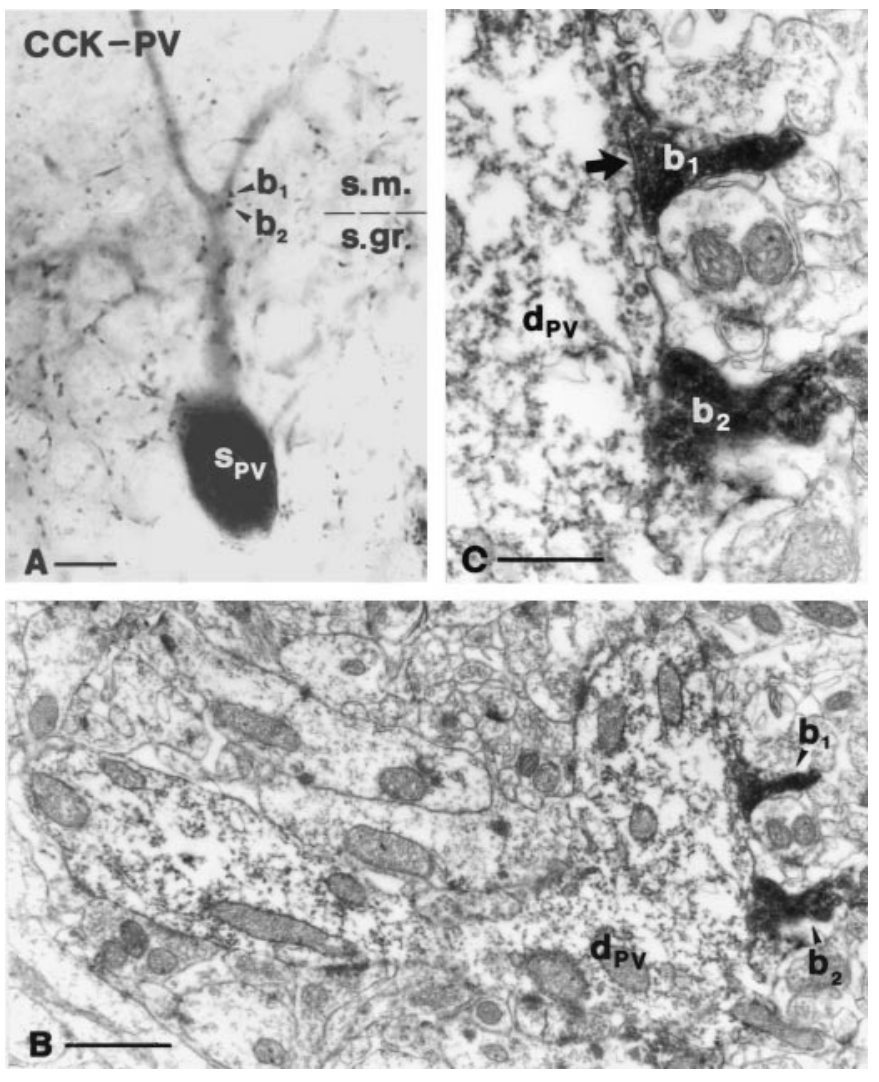

Figure 8. Interaction among CCK- and parvalbumin-positive neurons in the str. moleculare. Correlated light and electron microscopy demonstrate that the CCK-immunoreactive bouton $\mathrm{b}_{1}$ establishes a symmetrical synapse on the apical dendritic shaft of a pyramidal-like parvalbumin-positive interneuron. Five additional contacts were identified on the same dendrite. Note that the dark electron-dense DAB-Ni precipitate in $b_{1}$ and $b_{2}$ is easily distinguishable from the light DAB end product in the dendrite. For a color version of $A$, see supplementary information. Scale bars: $A, 10 \mu \mathrm{m} ; B, 1 \mu \mathrm{m}$; $C, 0.5 \mu \mathrm{m}$.

neuronal population in the hilus are qualitatively different from other cortical regions.

\section{Identity and arborization of CCK- and parvalbumin-positive interneurons}

Intracellular filling in vivo and in vitro demonstrated that the precise laminar distribution of axon arbors within and adjacent to the granule cell layer is quite heterogeneous in the dentate gyrus. The axons of certain basket cells in str. granulosum are strictly confined to this layer (Han, 1994; Mott et al., 1997; Lubke et al., 1998), whereas the axons of other interneurons arborize in the inner third of str. moleculare [the "classical" hilar neurons with axon in the commisural and association pathway (HICAP) cells] (Han et al., 1993; Buckmaster and Schwartzkroin, 1995b; Mott et al., 1997). Many cells have been described that arborize in both of these layers to a varying degree (Han et al., 1993; Mott et al., 1997; Sík et al., 1997; Lubke et al., 1998; Mott et al., 1999). Furthermore, some interneurons innervate both the dentate gyrus and the hilus (Han et al., 1993; Scharfman, 1995; Sík et al., 1997; Lubke et al., 1998) and even the CA3c region (Sík et al., 1997). On the basis of these previous results and the present reconstruction of CCKpositive axons, we can conclude that hilar perisomatic inhibitory terminals originate from basket cells with cell bodies situated in both the hilus and str. granulosum. Furthermore, these interneurons probably have collaterals in str. granulosum and inner str. moleculare to varying degrees. The confirmation of these results requires the combination of intracellular filling and simultaneous determination of neurochemical marker content. Regarding the neurochemical identity of the cells, we demonstrated that unlike in other hippocampal regions (Acsády et al., 1996a), CCK-containing large hilar boutons in the hilus derive from CCK-positive cells that do not colocalize VIP.

\section{Target selectivity of hilar basket cells}

Neurons can be broadly categorized as target selective or nonselective. Target-selective neurons contact only certain cell types within the entire neuron population (Freund and Antal, 1988; Freund et al., 1990; Acsády et al., 1996b; Gulyás et al., 1996), whereas nonselective cells innervate their targets in a quasirandom manner, commensurate with the distribution probability of the available targets (Sík et al., 1993, 1995; Katona et al., 1999a). Basket cells in other hippocampal regions are non-target-selective cells because within their termination zone they innervate pyramidal cells or other basket- or non-basket-type interneurons with multiple contacts (Sík et al., 1995; Cobb et al., 1997). The unexpected finding of the present study was that the hilar collaterals of CCK- and parvalbumin-containing basket cells contacted predominantly excitatory mossy cells and largely avoided other GABAergic neurons. On average, a single mossy cell received input from approximately 40 times more CCK-positive terminals than a hilar GABAergic cell (10.33 and 0.26 CCK terminals for mossy cells and GABAergic cells, respectively). This number is lower ( $\sim 15$ times) in the case of parvalbumin-positive terminals, but it is still in sharp contrast to the CA1 region where on their somatic region pyramidal cells are contacted by fewer GABAergic terminals than parvalbumin cells (Gulyás et al., 1999). This target selectivity cannot be explained by spatial factors because CCK- and parvalbuminpositive terminals as well as the various potential target cell types are distributed evenly in the hilus. In concert with our anatomical data in an in vivo study, the fast and slow IPSP conductance was found to be significantly smaller in hilar interneurons than in mossy cells, granule cells, or CA3 pyramidal cells (Buckmaster and Schwartzkroin, 1995a), suggesting limited inhibitory input. In contrast to the pronounced target selectivity in the hilar region, CCKand parvalbumin-positive neurons innervated each other via collaterals in str. granulosum and moleculare. This laminar difference in target selectivity is likely to be associated with the differential processing of excitation arriving on hilar versus str. moleculare dendrites of the same neurons (see below).

\section{Perisomatic inhibition and the vulnerability of hilar neurons}

Several hypotheses were put forward to explain the sensitivity of hilar neurons to various insults that damage most of the cell classes of this region transiently or permanently. These included versions of the excitotoxicity hypothesis, the excessive amount of kainate or Ca-permeable AMPA and NMDA receptors, cytoskeletal features of the neurons, or weak inhibition to balance large excitatory events (Houser, 1991; Schmidt-Kastner and Freund, 1991; Choi, 1992; Scharfman, 1992; Maglóczky and Freund, 1995; Tóth et al., 1997b). Rigorous anatomical testing of this last possibility has not been performed so far. Several in vivo and in vitro electrophysiological studies demonstrated GABA receptor-mediated evoked and spontaneous inhibitory responses in hilar mossy cells as well as in interneurons (Misgeld and Frotscher, 1986; Soltész et al., 1993; Soltész and Mody, 1994; Buckmaster and Schwartzkroin, 1995a; Sík et al., 1997), but others claimed that compared with granule cells and CA3 pyramidal neurons, hilar mossy cells receive only very weak inhibition (Livsey and Vicini, 1992; Scharfman, 1992, 1993). In the present study, both major basket cell types were shown to establish multiple perisomatic contacts around mossy cells. The number of terminals was estimated to be approximately 20. A single basket cell even via three synaptic boutons is able to block action potential initiation in a postsynaptic pyramidal cell in vitro (Miles et al., 1996). The powerful effect of perisomatic inhibitory synapses makes it unlikely that total lack of inhibition is a major factor in the sensitivity of mossy cells. However, it should be pointed out that compared with other hippocampal regions, the density of both CCK- and parvalbumin-positive terminals around mossy cells was always far below that around pyramidal or granule 


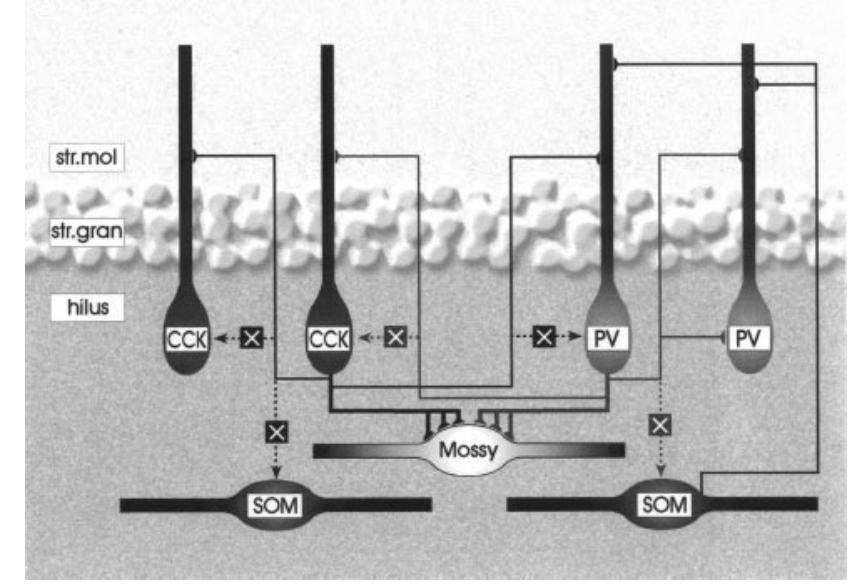

Figure 9. Schematic drawing demonstrating the interaction among various hilar cell types in the hilus and in str. moleculare. The connectivity of CCKand parvalbumin-positive cells is shown in black and gray, respectively. Dotted line and an X mark indicate lack of connection, whereas continuous lines show the verified synaptic interactions. The thickness of the lines corresponds to the strength of the connection. Note that besides a weak interaction among parvalbumin-containing cells, interneurons avoid each other in the hilus but have mutual connections in str. moleculare and str. granulosum. For clarity, only a single dendrite of each basket cell is drawn that reaches str. moleculare. Mossy cells receive innervation from both CCKand parvalbumin-positive basket cells, but hilar interneurons, many of which are somatostatin-containing, are avoided. The innervation of parvalbuminpositive cells by somatostatin-immunoreactive neurons was demonstrated by Katona et al. (1999).

cells. On the other hand, in the case of hilar interneurons, it is tempting to speculate that the paucity of perisomatic inhibition contributes to the loss of hilar GABAergic cells under pathological conditions.

\section{Functional implications}

Perisomatic inhibition is believed to be an important control mechanism for the temporal adjustment of the action potential (Lytton and Sejnowski, 1991; Buzsáki and Chrobak, 1995). From this perspective, one may predict that the timing of action potentials in mossy cells and especially hilar interneurons is less precise than in other parts of the hippocampus. Furthermore, mutual innervation of basket cells has been implicated in the generation of various cortical rhythms, including gamma oscillations (Bragin et al., 1995a; Buzsáki and Chrobak, 1995; Whittington et al., 1995). Indeed, computer modeling efforts suggest that a certain critical amount of innervation in an inhibitory network is critical for the emergence of the gamma rhythm (Whittington et al., 1995; Wang and Buzsáki, 1996). From this theoretical and experimental background, the low incidence of mutual innervation of the hilar interneuron population is especially unexpected because the power of gamma oscillation in the hippocampus is highest in the hilar region (Buzsáki et al., 1983; Bragin et al., 1995a). However, it should be emphasized that extracellular field activity in the hilus is caused mostly by the transmembrane currents generated by the numerous and laminarly arranged granule cells. The resolution of extracellular methods is not sufficient to separate fields generated by the granule cells and neurons in the hilus proper. Nevertheless, the current findings suggest that the different anatomical wiring of the hilar region should contribute to the electrical patterns of this region in a unique way.

Our present results point to an unusual asymmetry in the inhibitory control of various excitatory inputs to hilar interneurons (Fig. 9). Because perisomatic inhibitory cells largely ignore other GABAergic cells in the hilus, the mossy fiber input is able to exert a massive excitatory action on postsynaptic interneurons without the restraining influence of inhibition mediated by two major perisomatic inhibitory cell populations. Excitatory cortical and associational inputs to dentate interneurons, however, will always be under the control of feed-forward and feedback inhibition because GABAergic cells interact in str. granulosum and str. moleculare. Thus, recruitment of inhibition by granule cells is facilitated by two wiring characteristics. First, granule cells innervate more inhibitory than excitatory neurons (Acsády et al., 1998); second, innervation of hilar interneurons by basket cells is exceptionally sparse (present study). This is in sharp contrast to other cortical regions where principal cells innervate 8-10 times fewer interneurons than principal cells and the basket cells are interconnected (Sík et al., 1993). The unique wiring system of the hilar region probably results in one of the strongest inhibitory controls of principal cells in cortical systems. This effect is most evident during dentate spikes when most of the hilar GABAergic cells are strongly activated, whereas most mossy cells and pyramidal cells reduce their firing rate (Bragin et al., 1995b; Sík et al., 1997). Strong inhibitory action is necessary to produce sparse, discrete neuronal coding. Indeed, the dentate gyrus appears to transform the noisy spatial signal of the entorhinal cortex (Quirk et al., 1992) into the most discrete spatial code in the hippocampal formation, and granule cells have the lowest firing rate outside their preferred spatial field (Jung and McNaughton, 1993). We hypothesize that the strong activation of inhibitory circuits in the dentate gyrus is optimized to convert a denser cortical code into a sparse hippocampal representation.

\section{REFERENCES}

Acsády L, Arabadzisz D, Freund TF (1996a) Correlated morphological and neurochemical features identify different subsets of vasoactive intestinal polypeptide-immunoreactive interneurons in rat hippocampus. Neuroscience 73:299-315.

Acsády L, Görcs TJ, Freund TF (1996b) Different populations of vasoactive intestinal polypeptide-immunoreactive interneurons are specialized to control pyramidal cells or interneurons in the hippocampus. Neuroscience 73:317-334.

Acsády L, Katona I, Gulyás AI, Shigemoto R, Freund TF (1997) Immunostaining for substance $P$ receptor labels GABAergic cells with distinct termination patterns in the hippocampus. J Comp Neurol 378:320-336.

Acsády L, Kamondi A, Sík A, Freund T, Buzsáki G (1998) GABAergic cells are the major postsynaptic targets of mossy fibers in the rat hippocampus. J Neurosci 18:3386-3403.

Amaral DG (1978) A Golgi study of cell types in the hilar region of the hippocampus of the rat. J Comp Neurol 182:851-914.

Amaral DG, Dent JA (1981) Development of the mossy fibers of the dentate gyrus: I. A light and electron microscopic study of the mossy fibers and their expansions. J Comp Neurol 195:51-86.

Baffi J, Görcs T, Slowik F, Horvath M, Lekka N, Pasztor E, Palkovits M (1992) Neuropeptides in the human superior cervical ganglion. Brain Res 570:272-278.

Baimbridge KG, Miller JJ (1982) Immunohistochemical localization of calcium-binding protein in the cerebellum, hippocampal formation and olfactory bulb of the rat. Brain Res 245:223-229.

Baude A, Nusser Z, David J, Roberts B, Mulvihill E, McIlhinney RAJ, Somogyi P (1993) The metabotropic glutamate receptor (mGluR1 $\alpha$ ) is concentrated at perisynaptic membrane of neuronal subpopulations as detected by immunogold reaction. Neuron 11:771-787.

Blackstad TW, Kjaerheim A (1961) Special axodendritic synapses in the hippocampal cortex: electron and light microscopic studies on the layer of mossy fibres. J Comp Neurol 117:133-157.

Bragin A, Jandó G, Nádasdy Z, Hetke J, Wise K, Buzsáki G (1995a) Gamma $(40-100 \mathrm{~Hz})$ oscillation in the hippocampus of the behaving rat. J Neurosci 15:47-60.

Bragin A, Jandó G, Nádasdy Z, van Landeghem M, Buzsáki G (1995b) Dentate EEG spikes and associated interneuronal population bursts in the hippocampal hilar region of the rat. J Neurophysiol 73:1691-1705.

Buckmaster PS, Jongen-Relo AL (1999) Highly specific neuron loss preserves lateral inhibitory circuits in the dentate gyrus of kainate-induced epileptic rats. J Neurosci 19:9519-9529.

Buckmaster PS, Schwartzkroin PA (1995a) Interneurons and inhibition in the dentate gyrus of the rat in vivo. J Neurosci 15:774-789.

Buckmaster PS, Schwartzkroin PA (1995b) Physiological and morphological heterogeneity of dentate gyrus-hilus interneurons in the gerbil hippocampus in vivo. Eur J Neurosci 7:1393-1402.

Buzsáki G, Chrobak JJ (1995) Temporal structure in spatially organized neuronal ensembles: a role for interneuronal networks. Curr Opin Neurobiol 5:504-510. 
Buzsáki G, Leung LW, Vanderwolf CH (1983) Cellular bases of hippocampal EEG in the behaving rat. Brain Res 287:139-171.

Choi DW (1992) Excitotoxic cell death. J Neurobiol 23:1261-1276.

Claiborne BJ, Amaral DG, Cowan WM (1986) A light and electron microscopic analysis of the mossy fibers of the rat dentate gyrus. J Comp Neurol 246:435-458

Cobb SR, Buhl EH, Halasy K, Paulsen O, Somogyi P (1995) Synchronization of neuronal activity in hippocampus by individual GABAergic interneurons. Nature 378:75-78.

Cobb SR, Halasy K, Vida I, Nyiri G, Tamas G, Buhl EH, Somogyi P (1997) Synaptic effects of identified interneurons innervating both interneurons and pyramidal cells in the rat hippocampus. Neuroscience 79:629-648.

Cozzari C, Howard J, Hartman B (1990) Analysis of epitopes on choline acetyltransferase (Chat) using monoclonal antibodies. Soc Neurosci Abstr 16:200.

Dam AM (1980) Epilepsy and neuron loss in the hippocampus. Epilepsia 21:617-629.

Freund TF (1989) GABAergic septohippocampal neurons contain parvalbumin. Brain Res 478:375-381.

Freund TF, Antal M (1988) GABA-containing neurons in the septum control inhibitory interneurons in the hippocampus. Nature 336:170-173.

Freund TF, Buzsáki G (1996) Interneurons of the hippocampus. Hippocampus 6:345-470.

Freund TF, Gulyás AI, Acsády L, Görcs T, Tóth K (1990) Serotonergic control of the hippocampus via local inhibitory interneurons. Proc Natl Acad Sci USA 87:8501-8505.

Freund TF, Hájos N, Acsády L, Görcs TJ, Katona I (1997) Mossy cells of the rat dentate gyrus are immunoreactive for calcitonin gene-related peptide (CGRP). Eur J Neurosci 9:1815-1830.

Frotscher M, Seress L, Schwerdtfeger WK, Buhl E (1991) The mossy cells of the fascia dentata: a comparative study of their fine structure and synaptic connections in rodents and primates. J Comp Neurol 312:145-163.

Fukuda T, Aika Y, Heizmann CW, Kosaka T (1996) Dense GABAergic input on somata of parvalbumin-immunoreactive GABAergic neurons in the hippocampus of the mouse. Neurosci Res 26:181-194.

Gulyás AI, Görcs TJ, Freund TF (1990) Innervation of different peptidecontaining neurons in the hippocampus by GABAergic septal afferents. Neuroscience 37:31-44.

Gulyás AI, Hájos N, Freund TF (1996) Interneurons containing calretinin are specialized to control other interneurons in the rat hippocampus. J Neurosci 16:3397-3411.

Gulyás AI, Megias M, Emri Z, Freund TF (1999) Total number and ratio of excitatory and inhibitory synapses converging onto single interneurons of different types in the CA1 area of the rat hippocampus. J Neurosci 19:10082-10097.

Hájos N, Acsády L, Freund TF (1996) Target selectivity and neurochemical characteristics of VIP- immunoreactive interneurons in the rat dentate gyrus. Eur J Neurosci 8:1415-1431.

Hájos N, Papp EC, Acsády L, Levey AI, Freund TF (1998) Distinct interneuron types express $\mathrm{m} 2$ muscarinic receptor immunoreactivity on their dendrites or axon terminals in the hippocampus. Neuroscience $82: 355-376$

Han ZS (1994) Electrophysiological and morphological differentiation of chandelier and basket cells in the rat hippocampal formation: a study combining intracellular recording and intracellular staining with biocytin. Neurosci Res 19:101-110.

Han ZS, Buhl EH, Lorinczi Z, Somogyi P (1993) A high degree of spatial selectivity in the axonal and dendritic domains of physiologically identified local-circuit neurons in the dentate gyrus of the rat hippocampus. Eur J Neurosci 5:395-410.

Houser CR (1991) GABA neurons in seizure disorders: a review of immunocytochemical studies. Neurochem Res 16:295-308.

Jung MW, McNaughton BL (1993) Spatial selectivity of unit activity in the hippocampal granular layer. Hippocampus 3:165-182.

Katona I, Acsády L, Freund TF (1999a) Postsynaptic targets of somatostatin-immunoreactive interneurons in the rat hippocampus. Neuroscience 88:37-55.

Katona I, Sperlagh B, Sík A, Kafalvi A, Vizi ES, Mackie K, Freund TF (1999b) Presynaptically located CB1 cannabinoid receptors regulate GABA release from axon terminals of specific hippocampal interneurons. J Neurosci 19:4544-4558.

Katsumaru H, Kosaka T, Heizmann CW, Hama K (1988) Immunocytochemical study of GABAergic neurons containing the calcium-binding protein parvalbumin in the rat hippocampus. Exp Brain Res 72:347-362.

Kosaka T, Kosaka K, Tateishi K, Yanaihara Y, Hamaoka Y, Wu JJ, Hama K (1985) GABAergic neurons containing CCK-8-like and/or VIP-like immunoreactivities in the rat hippocampus and dentate gyrus. J Comp Neurol 239:420-430.

Kosaka T, Katsumaru H, Hama K, Wu JY, Heizmann CW (1987) GABAergic neurons containing the $\mathrm{Ca} 2+$-binding protein parvalbumin in the rat hippocampus and dentate gyrus. Brain Res 419:119-130.

Léránth C, Frotscher M (1986) Synaptic connections of cholecystokininimmunoreactive neurons and terminals in the rat fascia dentata: a combined light and electron-microscopic study. J Comp Neurol 254:51-64.

Léránth C, Szeidemann Z, Hsu M, Buzsáki G (1996) AMPA receptors in the rat and primate hippocampus: a possible absence of GluR2/3 subunits in most interneurons. Neuroscience 70:631-652.

Livsey CT, Vicini S (1992) Slower spontaneous excitatory postsynaptic currents in spiny versus aspiny hilar neurons. Neuron 8:745-755.

Lowenstein DH, Thomas MJ, Smith DH, McIntosh TK (1992) Selective vulnerability of dentate hilar neurons following traumatic brain injury: a potential mechanistic link between head trauma and disorders of the hippocampus. J Neurosci 12:4846-4853.

Lubke J, Frotscher M, Spruston N (1998) Specialized electrophysiological properties of anatomically identified neurons in the hilar region of the rat fascia dentata. J Neurophysiol 79:1518-1534.

Lytton WW, Sejnowski TJ (1991) Simulations of cortical pyramidal neurons synchronized by inhibitory interneurons. J Neurophysiol 66:1059-1079.

Maglóczky Z, Freund TF (1993) Selective neuronal death in the contralateral hippocampus following unilateral kainate injections into the CA3 subfield. Neuroscience 56:317-336.

Maglóczky Z, Freund TF (1995) Delayed cell death in the contralateral hippocampus following kainate injection into the CA3 subfield. Neuroscience 66:847-860.

Miles R, Tóth K, Gulyás AI, Hájos N, Freund TF (1996) Differences between somatic and dendritic inhibition in the hippocampus. Neuron $16: 815-823$.

Misgeld U, Frotscher M (1986) Postsynaptic-GABAergic inhibition of nonpyramidal neurons in the guinea-pig hippocampus. Neuroscience 19:193-206.

Moser EI (1996) Altered inhibition of dentate granule cells during spatial learning in an exploration task. J Neurosci 16:1247-1259.

Mott DD, Turner DA, Okazaki MM, Lewis DV (1997) Interneurons of the dentate-hilus border of the rat dentate gyrus: morphological and electrophysiological heterogeneity. J Neurosci 17:3990-4005.

Mott DD, Li Q, Okazaki MM, Turner DA, Lewis DV (1999) GABABreceptor-mediated currents in interneurons of the dentate-hilus border. J Neurophysiol 82:1438-1450.

Nitsch R, Soriano E, Frotscher M (1990) The parvalbumin-containing nonpyramidal neurons in the rat hippocampus. Anat Embryol 181:413-425.

Nunzi MG, Gorio A, Milan F, Freund TF, Somogyi P, Smith AD (1985) Cholecystokinin-immunoreactive cells form symmetrical synaptic contacts with pyramidal and nonpyramidal neurons in the hippocampus. J Comp Neurol 237:485-505.

Penttonen M, Kamondi A, Acsády L, Buzsáki G (1998) Gamma frequency oscillation in the hippocampus of the rat: intracellular analysis in vivo. Eur J Neurosci 10:718-728.

Quirk GJ, Muller RU, Kubie JL, Ranck Jr JB (1992) The positional firing properties of medial entorhinal neurons: description and comparison with hippocampal place cells. J Neurosci 12:1945-1963.

Ribak CE, Seress L, Amaral DG (1985) The development, ultrastructure and synaptic connections of the mossy cells of the dentate gyrus. J Neurocytol 14:835-857.

Ribak CE, Nitsch R, Seress L (1990) Proportion of parvalbumin-positive basket cells in the GABAergic innervation of pyramidal and granule cells of the rat hippocampal formation. J Comp Neurol 300:449-461.

Rogers JH (1989) Immunoreactivity for calretinin and other calciumbinding proteins in cerebellum. Neuroscience 31:711-721.

Scharfman HE (1992) Blockade of excitation reveals inhibition of dentate spiny hilar neurons recorded in rat hippocampal slices. J Neurophysiol 68:978-984.

Scharfman HE (1993) Characteristics of spontaneous and evoked EPSPs recorded from dentate spiny hilar cells in rat hippocampal slices. J Neurophysiol 70:742-757.

Scharfman HE (1995) Electrophysiological diversity of pyramidal-shaped neurons at the granule cell layer/hilus border of the rat dentate gyrus recorded in vitro. Hippocampus 5:287-305.

Schmidt-Kastner R, Freund TF (1991) Selective vulnerability of the hippocampus in brain ischemia. Neuroscience 40:599-636.

Seress L, Ribak CE (1983) GABAergic cells in the dentate gyrus appear to be local circuit and projection neurons. Exp Brain Res 50:173-182.

Shigemoto R, Nakaya Y, Nomura S, Ogawa-Meguro R, Ohishi H, Kaneko T, Nakanishi S, Mizuno N (1993) Immunocytochemical localization of rat substance $P$ receptor in the striatum. Neurosci Lett 153:157-160.

Sík A, Tamamaki N, Freund TF (1993) Complete axon arborization of a single CA3 pyramidal cell in the rat hippocampus, and its relationship with postsynaptic parvalbumin-containing interneurons. Eur J Neurosci 5:1719-1728.

Sík A, Penttonen M, Ylinen A, Buzsáki G (1995) Hippocampal CA1 interneurons: an in vivo intracellular labeling study. J Neurosci 15:6651-6665.

Sík A, Penttonen M, Buzsáki G (1997) Interneurons in the hippocampal dentate gyrus: an in vivo intracellular study. Eur J Neurosci 9:573-588.

Sloviter RS (1987) Decreased hippocampal inhibition and a selective loss of interneurons in experimental epilepsy. Science 235:73-76.

Sloviter RS, Nilaver G (1987) Immunocytochemical localization of GABA-, cholecystokinin-, vasoactive intestinal polypeptide-, and somatostatin-like immunoreactivity in the area dentata and hippocampus of the rat. J Comp Neurol 256:42-60.

Soltész I, Mody I (1994) Patch-clamp recordings reveal powerful GABAergic inhibition in dentate hilar neurons. J Neurosci 14:2365-2376. 
Soltész I, Bourassa J, Deschênes M (1993) The behavior of mossy cells of the rat dentate gyrus during theta oscillations in vivo. Neuroscience 57:555-564.

Somogyi P, Hodgson AJ, Smith AD, Nunzi MG, Gorio A, Wu JJ (1984) Different populations of GABAergic neurons in the visual cortex and hippocampus of cat contain somatostatin- or cholecystokininimmunoreactive material. J Neurosci 4:2590-2603.

Tauck DL, Nadler JV (1985) Evidence of functional mossy fiber sprouting in hippocampal formation of kainic acid-treated rats. J Neurosci 5:1016-1022.

Tóth K, Freund TF, Miles R (1997a) Disinhibition of rat hippocampal pyramidal cells by GABAergic afferents from the septum. J Physiol (Lond) 500:463-474.

Tóth Z, Hollrigel GS, Görcs T, Soltész I (1997b) Instantaneous perturbation of dentate interneuronal networks by a pressure wave-transient delivered to the neocortex. J Neurosci 17:8106-8117.
Tsou K, Mackie K, Sanudo-Pena MC, Walker JM (1999) Cannabinoid $\mathrm{CB} 1$ receptors are localized primarily on cholecystokinin-containing GABAergic interneurons in the rat hippocampal formation. Neuroscience 93:969-975.

Wang X-J, Buzsáki G (1996) Gamma oscillation by synaptic inhibition in a hippocampal interneuronal network model. $J$ Neurosci 16:6402-6413.

Whittington MA, Traub RD, Jeffreys JGR (1995) Synchronized oscillations in interneurons driven by metabotropic glutamate receptor activation. Nature 373:612-615.

Winson J, Abzug C (1978) Neuronal transmission through hippocampal pathways dependent on behavior. J Neurophysiol 41:716-732.

Ylinen A, Soltész I, Bragin A, Penttonen M, Sík A, Buzsáki G (1995) Intracellular correlates of hippocampal theta rhythm in identified pyramidal cells, granule cells, and basket cells. Hippocampus 5:78-90. 